Pakistan Journal of Education Vol.37, No.2, 2020, 79-95

\title{
Mental State Talk: Assessment through Wordless Picture Story Book Reading
}

\author{
Hafsa Khalil Toor ${ }^{*}$ \\ Rubina Hanif ${ }^{* *}$
}

\begin{abstract}
Mental state talk involves words that describe the mental world of individuals. These could be words that are about thoughts, feelings, desires, intentions, and emotions. There has been dearth of research in Pakistan assessing the parents and teachers' use of mental state talk in conversation with young children, commonly because of lack of assessment tool that are employed to measure the mental state talk in Pakistan. The present study aimed at validation and development of indigenous tool for the assessment of mental state talk of parents/teachers to use with children. Wordless picture story book reading was selected as one the various methods devised for mental state talk assessment; which facilitates interactions between parents/teachers and their children. For validation, Indigenous picture story books were reviewed for its content and modified through opinion of subject matter experts. Content and face validity of the story book were examined and found to be good. The finding concluded that finalized wordless picture story book has rich mental state content and has great potential to stimulate rich discourse on mental state talk. It will bridge the research gap and will promote as a good measurement instrument for research on mental state talk in Pakistan.
\end{abstract}

Keywords: mental state talk, parent child relationship, teacherpreschooler relationship, wordless picture book reading

Assistant Professor, Department of Psychology, Foundation University, Islamabad. Email: Hafsa_s16@nip.edu.pk

** Associate Professor, National Institute of Psychology, Quaid-i-Azam University, Islamabad. Email: drrubinahanif@nip.edu.pk 


\section{Introduction}

Mental State Talk (MST) is broadly defined as terms that describe the mental world and mind's contents of an individual(Jenkins, Turrell, Kogushi, Lollis, \& Ross, 2003; Misailidi, Papoudi, \& Brouzos, 2013; Ruffman, Slade, \& Crowe, 2002). Mental state talk are terms that are used by people to attribute physiological, emotional, perceptual, willing , cognitive, moral , socio-relational states of others (e.g. being hungry, see, desire, anger, knowing, judge, Helping) (Bretherton \& Beeghly, 1982; Symons, 2004).

Parents are first teacher of their children. From the birth, they provide the environment that enable children to make sense of their world. By interacting and labeling objects around them parents help children to build their own language. Studies have found that children who are exposed to terms that describe internal contents of others' mind like cognition, emotions and desires in their early years of life acquire understanding about their own MST in their early stage of life, which facilitate their theory of mind (ToM) task(Dunn, Brown, Slomkowski, Tesla, \& Youngblade, 1991; Jenkins et al., 2003).

Moreover, studies of father and mothers' MST with their children suggest that frequency of mental state terms, parents overall rates of talk may facilitate various areas of their children development(McElwain, Booth-LaForce, \& Wu, 2011; Symons, Fossum, \& Collins, 2006).

Similarly, Teachers' use of MSTis one of the important tools through which teacher can contribute to healthy and sensitive teacher child interaction. According to King and Paro (2015) teacher MST can help to reference children' MST through labeling and discussing mind processes. Thus understanding between teacher and child on inner state, may contribute to positive and healthy and trustworthy child and teacher relationship.

According toBandel, Aikens, Vogel, Boller, and Murphy (2014) young children who have rich and supportive interaction with their teachers in their classrooms, tends to perform better on emotional, behavioral, and cognitive development than children with less supportive teacher and classroom.

Also studies suggest that infants and toddlers who experience rich, supportive interactions with teachers tend to demonstrate higher levels of emotional, behavioral, and cognitive development than do children in less supportive classrooms (La Paro, Williamson, \& Hatfield, 2014; Mortensen \& Barnett, 2015; Ruzek, Burchinal, Farkas, \& Duncan, 2014).

Various methods devised for MST assessment. MST was assessed in naturalistic observation for father and mother(Jenkins et al., 2003), for mother (e.g. Brown, Donelan- McCall, \& Dunn, 1996; Nawaz \& Lewis, 2018), free 
play (Degotardi \& Torr, 2007; Laranjo, Bernier, Meins, \& Carlson, 2014; Slaughter, Peterson, \& Carpenter, 2008)talking about past events in conversation (Lagattuta \& Wellman, 2002; Laible, 2004; Laible \& Thompson, 2000), meal preparation(Ensor \& Hughes, 2008), mother to 'describe the child'(e.g. Lok \& McMahon, 2006)or requesting a friend 'describe your friend (Hughes \& Dunn, 1998) , pretend play (Dunn, Bretherton, \& Munn, 1987; Hughes \& Dunn, 1997), wordless picture books and pictures (Baptista et al., 2017; Doan \& Wang, 2010; Tarullo et al., 2016).

Despite growing body of research highlighting the importance of teacher and parents MST, and outcomes for children that are associated with the use of MST, there is dearth of research in Pakistan on assessment of MST of significant members of preschoolers. One of the reasons is the lack of validated assessment tool that are employed to measure the mental state talk. Thereby the present study aimed at finalizing a validated measure to fill the gap of current research in Pakistan.

The present study aimed to utilize a method that is convenient to use with parents as well as with teachers of Pakistan, moreover to utilize a method that elicits rich mental state talk. The method of naturalistic observation was used previously in Pakistan(Nawaz, 2015), which has practical constraint to use with fathers in Pakistan. Pictures and wordless picture storybooks are one of the most common methods that are employed to measure the MST. This method reflects mental word of the individual, where narrator of the story book attributes mental state to the story character and the parents or teachers keeps the child's mental state in mind in a safe environment ((Bruner ; Tager-Flusberg \& Sullivan; as cited in Bekar, Steele, Shahmoon-Shanok, \& Steele, 2018). Thereby, wordless book reading provides rich evidence about storyteller emotional, cognitive state, also. According to Koren Karie, Oppenheim, and Getzler Yosef (2004) and Macfie et al. (1999)wordless story book reading provide information about narrator interpersonal schemas, meaning making style and emotional regulation strategies.

The literature on importance of parental, teacher and other significant members mental state terms as a foundation and limited studies on mental state talk in Pakistan gives direction to rationale to present study . To bridge the gap, the present study endeavored to validate picture story books as an assessment tool for measuring MST. The picture story books that were used in previous studies lack indigenous content.

\section{Objectives of the Study}

For development and validation of indigenous tool for the assessment of mental state talk of parents/teachers to use with children the objectives of the study were 
1. To review the content of indigenous picture story books to use with father, mother and teacher for the measurement of MST.

2. To modify the picture story books for the use for present study.

3. To assess the maternal, paternal and teacher's mental state talk (desires, cognition and emotions) of preschoolers.

\section{Methodology}

The present study utilizes a procedure to validate and develop an indigenous procedure for measuring MST of parents and teacher to use with preschoolers. For this purpose subject matter experts were consulted, picture storybooks were modified, face and content validity was established to achieve the purpose. Figure 1 represents the flowchart of the development and validation of indigenous tool for the assessment of mental state talk of parents/teachers to use with preschooler.

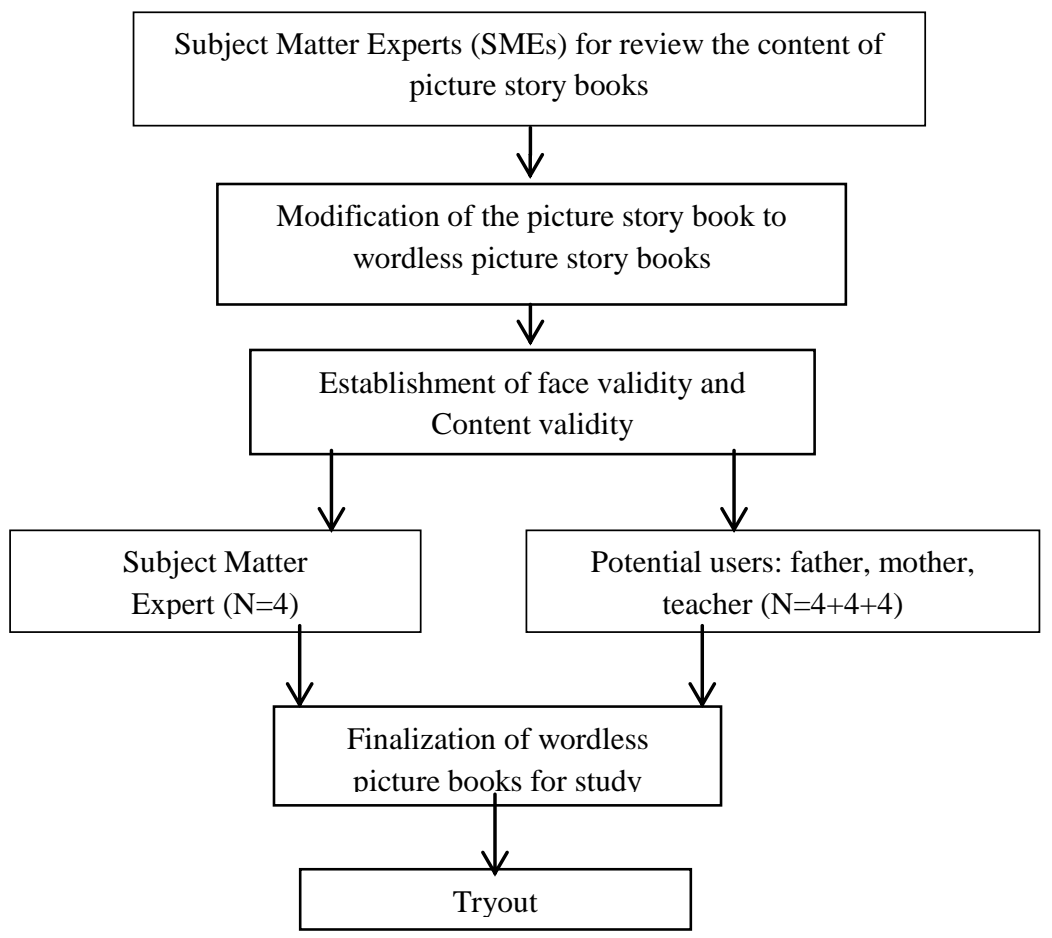

Figure 1: Flowchart of the development and validation of Indigenous tool for the assessment of mental state talk of parents/teachers to use with preschooler. 
For the selection of appropriate and valid tool for measuring the mental state talk of father, mother and teacher; First of all, three Subject Matter Experts (SMEs) were approached to review the content of picture story books, the experts were from the field of early childhood education and psychology. On the basis of literature review regarding the selection criteria of effective wordless picture storybook which stimulate rich discourse on mental state talk, the experts were briefed to select a books that (1) contain rich reference about the mental states of others conveyed through the interplay of pictures only that were describing the story; (2) Moreover that provides explicit and elaborative information about the mental state process of character of the story. (3) Further, the experts were asked to select the story where narrator (mother, father or teacher) attributes mental state to story characters and engage the preschooler, at its best. (4) They were also requested to check the appropriateness and cultural relevance of the story characters, dresses/ clothing, or situation so that child can relate to story characters. (5) and lastly that each story pictures book has the capacity to elicit equal amount of mental state words and books were comparable in terms of page numbers and type. Four picture story books were selected by the SMEs.

The picture books that were selected were further modified by omitting the words from the story books to make them wordless picture books to fulfill the purpose of present study. Moreover, face validity and content validity of picture story books were established by the panel of SMEs and the potential users (father, mother and teachers).

For face validity, panel of SMEs $(N=4)$ including education psychologist, child psychologist, experts in early child development and the users (father, mother and teachers) $(N=4+4+4)$ were asked to critically evaluate the four wordless picture story book that were selected earlier. The selection criteria of effective wordless story book and the purpose of study were clarified to them; they were requested to review each wordless picture book.

The content validity was computed out through quantitative measurement procedure by Lawshe (1975) by calculating Content Validity Ratio (CVR). For this purpose the selected four wordless picture story books were presented to SMEs $(N=4)$ and sample of potential users $(N=4+4+4)$ and were asked to evaluate the appropriateness on overall composition of book on the three point rating scale, which is (1) essential, (2) useful but not essential and (3) not necessary. Furthermore, Parents and teachers were requested to read the wordless picture story book to the preschoolers before evaluating the overall composition of modified picture storybook. This procedure helped to identify whether the books elicit rich reference about the mental states and suitable for 
preschoolers in Pakistan. In addition to this the parents and teachers were asked independently if they faced any difficulty in narrating a story with pictures only (without text).

On the basis of SMEs suggestion and CVR values, only three wordless picture story books were selected, which were in accordance with the selection criteria and was fulfilling the acceptable minimum CVR values (see table 1). Three wordless picture storybooks that were selected named as:

i) "Where Is Amma" by NandiniNayar

ii) "Raima and Rehan" by NandiniNayar

iii) "The Garbage Monster" by NigarNazar

These wordless picture books were finalized to administer for tryoutto measure the mental state talk of parents and teachers.

\section{Sample}

For the tryout, the sample comprised of 3 dyadic set of data which includes the mother, father, teacher $(\mathrm{N}=10+10+10)$ and preschooler (boys $=10$, girls $=10$ ). MST of teachers of the preschoolers was assessed in their respective schools and the data from parents were collected at their home from the city of Rawalpindi.

\section{Instrument}

Maternal, paternal and teachers' MST were assessed using wordless picture story books that were modified in initial phase, namely Where Is Amma(Nayar, 2010), Raima and Rehan(Nayar, 2017) and The Garbage Monster (Nazar, 2010b).

\section{Procedure}

The data was collected in two phases. In phase I, the schools were contacted for their permission to conduct research in their respective school. Teachers who gave consent and volunteered to participate were included in the current study. The demographic information about the teachers was obtained from the teachers. The teachers were asked to engage in story telling session with the preschoolers in a quiet room at their school.

In phase II, parents of preschoolers were contacted through school administration for their permission to visit their homes to measure MST, Visit was made only to those who gave consent to measure MST of both parents. The parents were informed about the procedure and the actual 
purpose of picture book story telling was not revealed before the assessment of MST. The demographic information about child and parents was obtained by the parents. The parents were asked individually to engage in wordless picture storytelling, with their child in a quiet room in their homes. During the story telling session it was made sure that father-child and mother-child are at ease and they have privacy to made interaction independently

The assignment of story books was counterbalanced among the father, mother and the teacher of the preschooler. The mother and father interaction with the child and teacher student (child/ preschooler) interactions were audiotaped, and then were transcribed. The transcribed interactions were then asses to assign code on mental state references.

\section{Data Analysis}

First the total number of words in each paternal, maternal and teacher's narrative was counted. This was the total word score, which captured father, mother and teachers' verbosity; in other words, the total word score reflected their tendency to express themselves concisely and in detail when narrating a story.

The MST was then coded into one of three exclusive categories, named as desire, cognition and emotions. Similar to previous study (Baptista et al., 2017) ,terms that were used for conversational purposes, for example I don't know, were not coded. Moreover, father mother or teachers' own repetitions of their conversation were not coded.

Cognitive terms. Cognitive terms included that express the thoughts, knowledge, and memories of listener, story teller or third person. The terms included in this domain were terms like think, believe, wonder, remember, know, forget, guess, pretend, expect etc.

Emotional terms. The mental state category emotion terms comprised of terms that indicates emotional state of the individual. Following the coding criteria of past researches(e.g. Jenkins et al., 2003), this category included all the variation of hurt, sad, angry, love, dislike, hurt, happy, fun, mad, afraid, surprise, excited, enjoy, bored etc. According to(Shatz, Wellman, \& Silber, 1983), emotion and desire terms were differentiated because of the emotional terms have behavioral manifestation.

Desire terms. These terms included the speakers' desires and worlds like want, wish, hope and care and variety of these terms(Bartsch \& Wellman, 1995; Jenkins et al., 2003; Shatz et al., 1983). These terms included goal directed behavior, for example the cat wants to sit down 
reflects want terms, I hope Ami (mother) will come soon, reflects hope and I care about my cat is example of terms like care.

Following previous studies(Baptista et al., 2017; Jenkins et al., 2003), utterances that reflects conversational devices, for example, I don't know, or which were repetitions of own or other's utterances were not coded.

The overall score from all three categories were coded as final score of MST. Tto control the differences in verbosity, father mother and teacher MST was calculated as proportion of total number of words on MST.

The coded mental state terms were then analyzed; by two independent raters to check the accuracy of codes. Inter-rater reliability was then assessed by calculating Cohen kappa for codes assigned (see table 2).

\section{Results}

The results of the study are as followed

\section{Face Validity Wordless Picture Story Books}

The SMEs and the potential users (father, mother and teachers) suggested that according to the selection criteria apparently only three of the wordless picture story books fulfilled the requirements. It was suggested by the panelist that one of the indigenous wordless picture story book Babloo: The Little Boy Who Didn't Like Books! (Nazar, 2010a)has less potential to stimulate rich discourse on mental state content after omitting the words from the original version of the story book. For validating the suggestions given by the panelist, CVR was computed.

\section{Content Validity Ratio of Wordless Picture Story Books}

Table 1

Content Validity Ratio of Wordless Picture Story Books as a Measure of Mental State Talk for Mother, Father and Teacher of Preschoolers

\begin{tabular}{ll}
\hline Wordless Picture Story Books & CVR \\
\hline Book 1 & 1.00 \\
Book 2 & .83 \\
Book 3 & $-.66^{\mathrm{a}}$ \\
Book 4 & .83 \\
\hline
\end{tabular}

Note. ${ }^{*} \mathrm{CVR}_{12 ; 0.05}=.56 ;{ }^{\mathrm{a}}$ values below the significant minimum.

For the three selected wordless picture books, both the pictures and overall composition of wordless storybooks had acceptable CVR values, with CVR indices of .83 to 1 . The wordless picture story book with negative CVR value -.66 was rejected. Lawshe(as cited in Cohen, 
Swerdlik, \& Phillips, 1996)recommended that if the amount of agreement of each item observed more than $5 \%$ of occurring by chance, such item should be eliminated. There were 12 panelists for showing agreement of item selection, so acceptable minimum CVR was .56. Based on the criteria story book 3 was eliminated due to negative CVR.

\section{Reliability Analysis for Coding of Mental State talk}

The Cohen kappa value was calculated for assessment of content of the father, mother and teacher mental state talk on mutually exclusive categories of: desire, emotions and cognitions by two trained raters and found to be substantial (.72).

Table 2

Descriptive statistics for mental state talk measures for mother, father and teacher with the preschooler $(N=10+10+10)$

\begin{tabular}{lllll}
\hline \multirow{3}{*}{ Father } & Measure & $\mathrm{M}$ & $\mathrm{SD}$ & Range \\
& Desire & 5.10 & 1.79 & $2-8$ \\
& Emotions & 12.30 & 5.22 & $3-21$ \\
& Cognitions & 33.50 & 8.03 & $14-42$ \\
\multirow{3}{*}{ Mother } & Total MST & 50.90 & 12.67 & $25-71$ \\
& Desire & 5.30 & 2.4 & $0-8$ \\
& Emotions & 13.80 & 6.07 & $5-23$ \\
& Cognitions & 32.60 & 11.72 & $10-52$ \\
Teacher & Total MST & 51.70 & 19.03 & $15-81$ \\
& Desire & 1.70 & 1.82 & $0-4$ \\
& Emotions & 9.70 & 2.49 & $4-13$ \\
& Cognitions & 42.70 & 8.79 & $38-59$ \\
& Total MST & 57.10 & 11.80 & $42-75$
\end{tabular}

Note. $\mathrm{M}=$ Mean, $\mathrm{S} . \mathrm{D}=$ Standard deviation, $\mathrm{MST}=$ Mental state talk

Table 2 gives information about means and standard deviations and range of mental state references (desire, emotions and cognitions) of father, mother and teacher with preschoolers. It also indicates total use of MST by mother, father, and teachers. 


\section{Discussion}

The objective of the present study was to validate an indigenous measure for assessment of mental state talk to use with preschoolers. For this purpose picture story books with indigenous content were modified and validated by following several valid and reliable procedures. The study tried out father, mother and teacher conversation in the context of story book reading after validation of the indigenous tool. The findings of these procedures largely suggest a valid tool to measure mental state talk of significant social agents of the preschoolers like father mother an teachers.

During review of literature, it was found that there were several methods employed for assessment of MST of parents, siblings and teachers in western culture as discussed earlier, which were not practical for Pakistani culture due to cultural differences in terms of mother-child, father- child and way of living. Moreover, there was dearth of assessment tool to be used in Pakistan with father, mother and teacher of the preschoolers. As mentioned earlier, method that was previously used in Pakistan for assessment of MST of mothers of preschoolers (Nawaz, 2015) were not effective to use with fathers. Hence all these practical problems for assessment of MST of parents and teachers of preschoolers in Pakistan, motivated the researcher to validate indigenous tool for assessment of MST, therefore this study will contribute to overcome the current problem.

The results of qualitative and quantitative validation procedure show that wordless picture story book selected in the study successfully assesses the MST of parents and teachers of preschoolers. The qualitative approach of content review of picture storybooks from SMEs according to selection criteria in the initial phase, enabled to identify the few of the potential picture story books to elicit and stimulate MST. However, only three of the books were selected and finalized in subsequent stage of validation. To fulfill the objective of the study, the textual content from the picture story books were removed during phase of modification, which led different results as expected during the phase of establishing Face validity. It was suggested by panelist to select picture books that help and promote in interpreting character's thoughts feelings and desires without textual support.

To quantitatively validate the recommendation, Content validity was established following the Lawshe (1975)) method which is another important parameter of validity. The results supported the findings of qualitative validation. Only three wordless picture story books with acceptable CVR were finalized were selected. These findings of 
qualitative and quantitative validation procedures revealed that the third story book fulfills few of the basic objectives only. The panelists suggested that the story book was culturally relevant and was grasping the preschooler attention but was not able to elicit MST without the textual support.

In accordance with the objectives of the present study, after finalization assessment tool for MST, it was tried out on a small sample of father, mother and teacher of the preschoolers $(N=10+10+10)$. Parents and teacher were asked to engage with a child in story telling session. Following ethical consideration their story telling sessions were audio taped and transcribed. In accordance with previous studies(Baptista et al., 2017; Bartsch \& Wellman, 1995; Jenkins et al., 2003; Ruffman et al., 2002), MST were coded into mutually exclusive category of emotions, desires and cognitions. The interrater reliability on the coded category was established and the results showed that Kappa value .72, which according Cohen (1960) to besubstantial.

The descriptive results on MST of father, mother and teachers showed not only the effectivity of the wordless story books also, like previous studies (LaBounty, Wellman, Olson, Lagattuta, \& Liu, 2008)this study suggest that mother, father and teachers differ in their use of MST like desire ,emotions and cognitive terms; Moreover, the results study found that mother talk more frequently about mental states as compare to father. These findings are consistent with pervious findings of Jenkins et al. (2003). However, in their research; father and mother were not assessed independently. Due to limited sample size of the present study these differences were not significant. Consistent with previous studies (King, 2013; Misailidi et al., 2013)this study found that teachers not only use more terms with preschoolers as compare to mothers but also teachers were likely to use more cognition terms as compare to other terms.

\section{Conclusion and Future Direction}

The present study aimed at validating assessment tool for measurement of MST to be used with preschoolers. The findings of the study led to conclude that various validating procedure reflects that finalized wordless picture story books were found to promote paternal, maternal and teacher mental state talk. These wordless picture story books have rich mental state contents and have immense power to stimulate conversation about the pictures in the story book. Moreover, the validated books deliver explicit and elaborative information of the story character and it involves and takes the attention of the preschoolers 
and reading books provide comfortable environment where parents can reflect about their internal states

It can be concluded that present study will fill the gap and difficulty for measurement of MST of parents' and teachers of preschoolers for Pakistani population. It will open avenue for researcher in Pakistan to add to growing body of research on importance of words and language of significant members of the preschooler, which contributes to social, moral, cognitive development of preschoolers.

For present study the sample size was compromised (10 quadratic set of father, mother, teacher and preschooler), which included the audio recording of independent interaction of each father mother and teacher with the preschooler. For practical reasons it was difficult to collect large set of data for present research. Also, in qualitative studies the data is usually drawn from fewer participants as they include detailed and contextualized data (Levitt et al., 2018). It is recommended that , future researches should take more sample as, larger sample will provide better picture while studying MST of significant others of the preschoolers.

Further, it is recommended that teachers and parents should be directed to utilize their knowledge while conversing with their children, as pervious researches support the idea that MST of parents and teachers contributes to children social, cognitive and emotional development. Further, in future a large sample size should be taken to study MST and to study how it contributes to different domain of child development. It is strongly recommended that a book reading survey should be conducted before using this indigenous validated tool to get a better picture.

\section{Acknowledgment}

We would also like to show our gratitude to Ms. Nigar Nazar, the story writer and artist of "Garbage Monster"for providing her story books for the present research. The story book "Raima and Rehan" was "reproduced with permission of Oxford University Press Pakistan (C) Oxford University Press'; Also we are thankful to Tulika Books India for their permission to use "Where Is Amma?". 


\section{References}

Bandel, E., Aikens, N., Vogel, C. A., Boller, K., \& Murphy, L. (2014). Observed quality and psychometric properties of the CLASS-T in the Early Head Start Family and Child Experiences Survey: Mathematica Policy Research.

Baptista, J., Osório, A., Martins, E. C., Castiajo, P., Barreto, A. L., Mateus, V., . . . Martins, C. (2017). Maternal and paternal mental- state talk and executive function in preschool children. Social Development, 26(1), 129-145.

Bartsch, K., \& Wellman, H. M. (1995). Children talk about the mind. Newyork: Oxford University Press.

Bekar, O., Steele, M., Shahmoon-Shanok, R., \& Steele, H. (2018). Mothers' mental state talk and preschool children's social-behavioral functioning: A multidimensional account. Journal of Infant, Child, and Adolescent Psychotherapy, 17(2), 119-133.

Bretherton, I., \& Beeghly, M. (1982). Talking about internal states: The acquisition of an explicit theory of mind. Developmental Psychology, 18(6), 906.

Brown, J. R., Donelan- McCall, N., \& Dunn, J. (1996). Why talk about mental states? The significance of children's conversations with friends, siblings, and mothers. Child Development, 67(3), 836-849.

Cohen, R. J., Swerdlik, M. E., \& Phillips, S. M. (1996). Psychological testing and assessment: An introduction to tests and measurement: Mayfield Publishing Co.

Degotardi, S., \& Torr, J. (2007). A longitudinal investigation of mothers' mind- related talk to their 12- to 24- month- old infants. Early Child Development and Care, 177(6-7), 767-780.

Doan, S. N., \& Wang, Q. (2010). Maternal discussions of mental states and behaviors: Relations to emotion situation knowledge in European American and immigrant Chinese children. Child Development, 81(5), 1490-1503.

Dunn, J., Bretherton, I., \& Munn, P. (1987). Conversations about feeling states between mothers and their young children. Developmental Psychology, 23(1), 132. 
Dunn, J., Brown, J., Slomkowski, C., Tesla, C., \& Youngblade, L. (1991). Young children's understanding of other people's feelings and beliefs: Individual differences and their antecedents. Child Development, 62(6), 1352-1366.

Ensor, R., \& Hughes, C. (2008). Content or connectedness? Motherchild talk and early social understanding. Child Development, 79(1), 201-216.

Hughes, C., \& Dunn, J. (1997). "Pretend you didn't know": Preschoolers' talk about mental states in pretend play. Cognitive Development, 12(4), 477-497.

Hughes, C., \& Dunn, J. (1998). Understanding mind and emotion: longitudinal associations with mental-state talk between young friends. Developmental Psychology, 34(5), 1026.

Jenkins, J. M., Turrell, S. L., Kogushi, Y., Lollis, S., \& Ross, H. S. (2003). A longitudinal investigation of the dynamics of mental state talk in families. Child Development, 74(3), 905-920.

King, E. K. (2013). Teachers' Expression of Mental State Talk in Head Start Classrooms. University of North Carolina at Greensboro.

Koren- Karie, N., Oppenheim, D., \& Getzler- Yosef, R. (2004). Mothers who were severely abused during childhood and their children talk about emotions: Co- construction of narratives in light of maternal trauma. Infant Mental Health Journal: Official Publication of The World Association for Infant Mental Health, 25(4), 300-317.

La Paro, K. M., Williamson, A. C., \& Hatfield, B. (2014). Assessing quality in toddler classrooms using the CLASS-Toddler and the ITERS-R. Early Education and Development, 25(6), 875-893.

LaBounty, J., Wellman, H. M., Olson, S., Lagattuta, K., \& Liu, D. (2008). Mothers' and fathers' use of internal state talk with their young children. Social Development, 17(4), 757-775.

Lagattuta, K. H., \& Wellman, H. M. (2002). Differences in early parentchild conversations about negative versus positive emotions: implications for the development of psychological understanding. Developmental Psychology, 38(4), 564.

Laible, D. J. (2004). Mother-child discourse surrounding a child's past behavior at 30 months: Links to emotional understanding and early 
conscience development at 36 months. Merrill-Palmer Quarterly (1982-), 159-180.

Laible, D. J., \& Thompson, R. A. (2000). Mother-child discourse, attachment security, shared positive affect, and early conscience development. Child Development, 71(5), 1424-1440.

Laranjo, J., Bernier, A., Meins, E., \& Carlson, S. M. (2014). The roles of maternal mind-mindedness and infant security of attachment in predicting preschoolers' understanding of visual perspective taking and false belief. Journal of Experimental Child Psychology, 125, 4862.

Lawshe, C. H. (1975). A quantitative approach to content validity 1. Personnel Psychology, 28(4), 563-575.

Levitt, H. M., Bamberg, M., Creswell, J. W., Frost, D. M., Josselson, R., \& Suárez-Orozco, C. (2018). Journal article reporting standards for qualitative primary, qualitative meta-analytic, and mixed methods research in psychology: The APA Publications and Communications Board task force report. American Psychologist, 73(1), 26.

Lok, S. M., \& McMahon, C. A. (2006). Mothers' thoughts about their children: Links between mind- mindedness and emotional availability. British Journal of Developmental Psychology, 24(3), 477-488.

Macfie, J., Toth, S. L., Rogosch, F. A., Robinson, J., Emde, R. N., \& Cicchetti, D. (1999). Effect of maltreatment on preschoolers' narrative representations of responses to relieve distress and of role reversal. Developmental Psychology, 35(2), 460.

McElwain, N. L., Booth-LaForce, C., \& Wu, X. (2011). Infant-mother attachment and children's friendship quality: Maternal mental-state talk as an intervening mechanism. Developmental Psychology, 47(5), 1295.

Misailidi, P., Papoudi, D., \& Brouzos, A. (2013). Mind what teachers say: Kindergarten teachers' use of mental state language during picture story narration. Early Education \& Development, 24(8), 1161-1174.

Mortensen, J. A., \& Barnett, M. A. (2015). Teacher-child interactions in infant/toddler child care and socioemotional development. Early Education and Development, 26(2), 209-229. 
Nawaz, S. (2015). Role of Language Interaction in Children's Theory of Mind among Preschoolers. Quaid-i-Azam University Islamabad.

Nawaz, S., \& Lewis, C. (2018). Mother-child conversation and social understanding in Pakistan. International Journal of Behavioral Development, 42(5), 496-505.

Nayar, N. (2010). Where is amma? Islamabad, Pakistan: Oxford University press.

Nayar, N. (2017). Raima and Rehan. islamabad, Pakistan Oxford University Press.

Nazar, N. (2010a). Babloo: The Little Boy Who Didn't Like Books! Islamabad, Pakistan.: Oxford University press.

Nazar, N. (2010b). Grabage Monster. Islamabad, Pakistan: Oxford University press.

Ruffman, T., Slade, L., \& Crowe, E. (2002). The relation between children's and mothers' mental state language and theory- of- mind understanding. Child Development, 73(3), 734-751.

Ruzek, E., Burchinal, M., Farkas, G., \& Duncan, G. J. (2014). The quality of toddler child care and cognitive skills at 24 months: Propensity score analysis results from the ECLS-B. Early childhood research quarterly, 29(1), 12-21.

Shatz, M., Wellman, H. M., \& Silber, S. (1983). The acquisition of mental verbs: A systematic investigation of the first reference to mental state. Cognition, 14(3), 301-321.

Slaughter, V., Peterson, C. C., \& Carpenter, M. (2008). Maternal talk about mental states and the emergence of joint visual attention. Infancy, 13(6), 640-659.

Symons, D. K. (2004). Mental state discourse, theory of mind, and the internalization of self-other understanding. Developmental Review, 24(2), 159-188.

Symons, D. K., Fossum, K. L. M., \& Collins, T. K. (2006). A longitudinal study of belief and desire state discourse during motherchild play and later false belief understanding. Social Development, 15(4), 676-692.

Tarullo, A. R., Youssef, A., Frenn, K. A., Wiik, K., Garvin, M. C., \& Gunnar, M. R. (2016). Emotion understanding, parent mental state 
language, and behavior problems in internationally adopted children. Development and Psychopathology, 28(2), 371-383.

\section{Citation of this Article:}

Toor, H. K., \& Hanif, R. (2020). Mental state talk: Assessment through wordless picture story book reading Pakistan Journal of Education, 37 (2), 79-95. 
